\section{A) Check for updates}

Cite this: Food Funct., 2020, 11, 5875

\title{
Prebiotic galactooligosaccharides production from lactose and lactulose by Lactobacillus delbrueckii subsp. bulgaricus CRL450 $\uparrow$
}

\author{
Agustina Fara, ${ }^{a}$ Carlos Sabater, ${ }^{b}$ Jorge Palacios, (D) a Teresa Requena, (D) c \\ Antonia Montilla (D) *b and Gabriela Zárate (D) ${ }^{a, d}$
}

\begin{abstract}
Galactooligosaccharides (GOS) are useful dietary ingredients recognized worldwide as prebiotics. In the present study, we evaluated the $\beta$-galactosidase ( $\beta$-gal) activity of a panel of lactic acid bacteria (LAB) in order to select strains for the synthesis of oligosaccharides from lactose (GOS) and lactulose (OsLu) with a potential prebiotic effect. Fifteen strains out of 20 were able to grow on lactose and showed $\beta$-gal activities between 0.03 and $2.06 \mathrm{U} \mathrm{mg}^{-1}$, whereas eleven were able to synthesize GOS. Lactobacillus delbrueckii subsp. bulgaricus CRL450, the strain with the highest $\beta$-gal activity, synthesized a maximum of 41.3\% GOS and $21.0 \%$ OsLu from lactose and lactulose, respectively, with $\beta$ - $(1 \rightarrow 6)$ and secondary $\beta$ - $(1 \rightarrow$ 3) linkages. When these compounds were tested without purifying, as carbon sources for the development of recognized probiotics and the producer strain, high growth was observed compared to non-prebiotic sugars like glucose and lactose. When the purified oligosaccharides were tested, the bacterial growth decreased, but the microorganisms displayed metabolic activity evidenced by the consumption of carbohydrates and the production of lactic acid. Additionally, the purified oligosaccharides demonstrated a bifidogenic effect. The obtained results support the potential of L. delbrueckii subsp. bulgaricus CRL450 for the production of the prebiotics GOS and OsLu and encourage the optimization of their synthesis for the design of new functional food ingredients.
\end{abstract}

Received 11th April 2020 Accepted 17th June 2020 DOI: $10.1039 /$ d0fo00942c rsc.li/food-function ing the metabolism of lactose in the gut with the consequent alleviation of intolerance symptoms. ${ }^{2,3}$ These technological and probiotic properties are based on the hydrolysis of milk sugar by $\beta$-gal, which releases its monosaccharides glucose and galactose. However, this enzyme also catalyzes transgalactosylation reactions that allow the synthesis of galactooligosaccharides (GOS) ${ }^{4,5}$ GOS are defined as nondigestible carbohydrates, formed by two to five galactose monomers and often a unit of terminal glucose linked by glycosidic bonds that exert prebiotic effects in consumers. ${ }^{6,7}$ Prebiotics are substrates that are selectively utilized by host microorganisms conferring a health benefit. ${ }^{8}$ Among them, GOS have proven to be useful for the modulation of the colonic microbiota toward a healthy balance, which usually involves the increase of bifidobacteria and lactobacilli and the decrease of less desirable microorganisms such as clostridia, bacteroides and enterobacteria pathobionts. Other health benefits ascribed to GOS include the inhibition of the attachment of pathogenic bacteria to the colonic epithelium, reduction of serum cholesterol and blood pressure, prevention of colon cancer and enhancement of immunity. ${ }^{8,9}$ In addition, GOS have other useful properties as food ingredients/sweeteners: low-glycemic index, no-cariogenic, low-calorie and resistant to acidic $\mathrm{pH}$ values and high 
temperatures (pasteurization and baking). ${ }^{10,11}$ Besides, GOS can protect probiotic strains during preservation processes like freeze-drying, obtaining a self-protected symbiotic formulation. ${ }^{7}$ In view of all of these properties and the high demand for healthy foods by consumers, there is a growing commercial interest in the food industry for producing GOS as functional ingredients for a wide range of products such as infant foods, dairy products and fruit-based drinks.

In addition to GOS, lactulose and its derived oligosaccharides (OsLu) can be enzymatically synthesized by microbial $\beta$-gal ${ }^{12-16}$ but, depending on the enzyme origin and the reaction conditions, the yield, composition and linkages between the monomers of the formed oligosaccharides may vary affecting their properties.

Previous studies have shown the synthesis, structural characterization, and prebiotic effects of GOS and OsLu produced by fungal $\beta$-gal from Aspergillus and Kluyveromyces species ${ }^{12,13,15-18}$ and bacteria like Bacillus circulans, ${ }^{19,20}$ Propionibacterium acidipropionici $^{21}$ and Bifidobacterium spp. ${ }^{22-24}$ LAB have been studied intensively with respect to their enzymes because of their general recognition as safe (GRAS) and qualified presumption of safety (QPS) status that allow the use of the enzymes derived from these organisms without extensive purification in foodrelated applications. However, only a few studies have focused on the transgalactosidase activity of the $\beta$-gal from Lactobacillus strains for GOS production. This ability has been reported for Lactobacillus reuteri, ${ }^{25}$ L. acidophilus, ${ }^{26,27}$ L. $_{\text {plantarum }}{ }^{28,29}$ and L. bulgaricus. ${ }^{30}$ In this respect, it has been suggested that the $\beta$-gal from probiotics might produce GOS structures that have special prebiotic effects, specifically targeting selected probiotic strains. ${ }^{31}$ Therefore, the aim of this work was to assess the transgalactosidase activity of different Lactobacillus strains isolated from Argentinian products in order to determine which strain leads to the highest GOS and OsLu yields. Then, the prebiotic potential of these oligosaccharides was tested on recognized probiotic strains by assessing their growth and metabolic activity evidenced by carbohydrate consumption and lactic acid production.

\section{Materials and methods}

\subsection{Reagents}

The standards (glucose, galactose, fructose, lactose, lactulose, raffinose and stachyose), $o$-nitrophenyl- $\beta$-D-galactopyranoside (ONPG), $\beta$-gal from Aspergillus oryzae, activated charcoal and thin layer chromatography (TLC) plates were purchased from Sigma-Aldrich (St Louis, MO, USA). Lactozym®Pure $6500 \mathrm{~L}$ (Lactozym), a $\beta$-gal from Kluyveromyces lactis was provided by Novozymes (Dittingen, Switzerland). Vivinal®-GOS syrup (Vivinal, Friesland Campina Domo, The Netherlands) contains approximately $75 \%$ dry matter (DM), $59 \%$ of GOS, $21 \%$ of glucose, $19 \%$ of lactose and $1.4 \%$ of galactose respect to quantified carbohydrates. Aspergillus oryzae-OsLu (Ao-OsLu) synthesized from lactulose were composed by $81 \% \mathrm{DM}, 58 \% \mathrm{Ao}$ OsLu (23\% disaccharides different to lactulose, mainly 6-galactobiose; $28 \%$ trisaccharides, mainly 6'-galactosyl-lactulose and $8 \%$ tetrasaccharides), $24 \%$ lactulose, $14 \%$ galactose and $4 \%$ lactose respect to quantified carbohydrates. ${ }^{10,13,17}$ The culture media MRS and acetonitrile HPLC grade were obtained from Merck (Darmstadt, Germany).

\subsection{Bacterial strains and culture media}

Twenty Lactobacillus strains belonging to the culture collection of CERELA-CONICET (CRL), Argentina, were tested in the present study (Table 1). The probiotic strains Lactobacillus

Table 1 Growth parameters, $\beta$-gal activity and qualitative GOS production by lactobacilli developed $24 \mathrm{~h}$ at $37^{\circ} \mathrm{C}$ on MRS containing lactose as carbon source. Data are the means of two independent assays $( \pm S D)$

\begin{tabular}{|c|c|c|c|c|c|c|c|}
\hline CODE & Strain $^{a}$ & Origin & $\mathrm{OD}_{600} \max$ & $\mathrm{pH}$ & $\beta$-Gal activity ( $\mathrm{U} \mathrm{mg}^{-1}$ ) & $\mathrm{OD}_{420}$ slope & GOS synthesis \\
\hline CRL 43 & L. acidophilus & Tafi cheese & - & - & - & - & - \\
\hline CRL 450 & L. bulgaricus & Yoghurt & $0.54 \pm 0.09^{\mathrm{a}, \mathrm{b}}$ & $4.20 \pm 0.10^{\mathrm{a}, \mathrm{b}}$ & $2.06 \pm 0.02^{\mathrm{a}}$ & $0.238^{\mathrm{a}}$ & + \\
\hline CRL 494 & L. bulgaricus & Yoghurt & $0.47 \pm 0.02^{\mathrm{a}, \mathrm{b}}$ & $4.53 \pm 0.04^{\mathrm{a}, \mathrm{b}}$ & $0.24 \pm 0.00^{\mathrm{a}, \mathrm{b}}$ & $0.084^{\mathrm{c}, \mathrm{d}}$ & + \\
\hline CRL 468 & L. bulgaricus & Yoghurt & $0.28 \pm 0.03^{\mathrm{b}}$ & $4.17 \pm 0.06^{\mathrm{a}, \mathrm{b}}$ & $0.40 \pm 0.00^{\mathrm{a}, \mathrm{b}}$ & $0.079^{\mathrm{c}, \mathrm{d}}$ & + \\
\hline CRL 958 & L. bulgaricus & Yoghurt & $0.37 \pm 0.00^{\mathrm{a}, \mathrm{b}}$ & $4.23 \pm 0.06^{\mathrm{a}, \mathrm{b}}$ & $0.27 \pm 0.00^{\mathrm{a}, \mathrm{b}}$ & $0.038^{\mathrm{e}, \mathrm{f}}$ & + \\
\hline CRL 574 & L. fermentum & Infant feces & - & - & - & - & - \\
\hline CRL 76 & L. paracasei & Commercial cheese & $0.58 \pm 0.03^{\mathrm{a}, \mathrm{b}}$ & $4.07 \pm 0.06^{\mathrm{a}, \mathrm{b}}$ & $0.25 \pm 0.00^{\mathrm{a}, \mathrm{b}}$ & $0.059^{\mathrm{d}, \mathrm{e}}$ & + \\
\hline CRL 143 & L. paracasei & Commercial cheese & $0.58 \pm 0.02^{\mathrm{a}, \mathrm{b}}$ & $5.00 \pm 0.03^{\mathrm{a}, \mathrm{b}}$ & $0.03 \pm 0.00^{\mathrm{b}}$ & $0.003^{g}$ & - \\
\hline CRL 200 & L. paracasei & Tafí cheese & $0.99 \pm 0.01^{\mathrm{a}}$ & $4.09 \pm 0.08^{\mathrm{a}, \mathrm{b}}$ & $0.86 \pm 0.01^{\mathrm{a}, \mathrm{b}}$ & $0.092^{c}$ & + \\
\hline CRL 1501 & L. paracasei & Tomato extract & - & - & - & - & - \\
\hline CRL 41 & L. plantarum & Tafí cheese & $0.55 \pm 0.02^{\mathrm{a}, \mathrm{b}}$ & $5.34 \pm 0.08^{\mathrm{a}}$ & $0.26 \pm 0.02^{\mathrm{a}, \mathrm{b}}$ & $0.032^{\mathrm{f}}$ & - \\
\hline CRL 58 & L. plantarum & Tafí cheese & - & - & - & - & - \\
\hline CRL 93 & L. plantarum & Tafi cheese & $0.56 \pm 0.03^{\mathrm{a}, \mathrm{b}}$ & $4.42 \pm 0.12^{\mathrm{a}, \mathrm{b}}$ & $0.03 \pm 0.00^{\mathrm{b}}$ & $0.004^{\mathrm{g}}$ & - \\
\hline CRL 972 & L. plantarum & Cabbage & $0.66 \pm 0.00^{\mathrm{a}, \mathrm{b}}$ & $4.90 \pm 0.11^{\mathrm{a}, \mathrm{b}}$ & $0.11 \pm 0.00^{\mathrm{b}}$ & $0.020^{f, g}$ & + \\
\hline CRL 1076 & L. plantarum & Pea & - & - & - & - & - \\
\hline CRL 1234 & L. plantarum & Cabbage & $0.82 \pm 0.10^{\mathrm{a}, \mathrm{b}}$ & $3.81 \pm 0.10^{\mathrm{b}}$ & $0.13 \pm 0.02^{\mathrm{b}}$ & $0.005^{\mathrm{g}}$ & + \\
\hline CRL 1775 & L. plantarum & Olive & $0.48 \pm 0.01^{\mathrm{a}, \mathrm{b}}$ & $4.45 \pm 0.04^{\mathrm{a}, \mathrm{b}}$ & $0.20 \pm 0.02^{\mathrm{a}, \mathrm{b}}$ & $0.093^{c}$ & - \\
\hline CRL 2211 & L. plantarum & Pea & $0.25 \pm 0.04^{\mathrm{b}}$ & $4.07 \pm 0.06^{\mathrm{a}, \mathrm{b}}$ & $0.65 \pm 0.02^{\mathrm{a}, \mathrm{b}}$ & $0.162^{\mathrm{b}}$ & + \\
\hline CRL 1101 & L. reuteri & Adult human gut & $0.46 \pm 0.01^{\mathrm{a}, \mathrm{b}}$ & $4.15 \pm 0.04^{\mathrm{a}, \mathrm{b}}$ & $0.06 \pm 0.01^{\mathrm{b}}$ & $0.014^{\mathrm{f}, \mathrm{g}}$ & + \\
\hline CRL 1880 & L. sakei & Sausage & $0.54 \pm 0.00^{\mathrm{a}, \mathrm{b}}$ & $4.72 \pm 0.04^{\mathrm{a}, \mathrm{b}}$ & $0.05 \pm 0.00^{\mathrm{b}}$ & $0.002^{\mathrm{g}}$ & + \\
\hline
\end{tabular}

${ }^{a}$ Lactobacillus strains, codes and origin. ${ }^{\mathrm{a}, \mathrm{b}, \mathrm{c}, \mathrm{d}, \mathrm{e}, \mathrm{f}, \mathrm{g}}$ Statistically significant differences between strains. 
casei CRL431® (CERELA-CONICET, Chr.Hansen) and Bifidobacterium animalis subsp. lactis BB-12® (Chr.Hansen) and the enterobacteria Escherichia coli C3 (Institute of Microbiology "Luis Verna" of the University of Tucumán) were used to assay the prebiotic activity of oligosaccharides. The strains, stored at $-20{ }^{\circ} \mathrm{C}$ in $10 \%(\mathrm{w} / \mathrm{v})$ reconstituted skim milk containing $5 \%$ yeast extract and $10 \%$ glycerol, were activated in MRS broth at $37{ }^{\circ} \mathrm{C}$ by three successive transfers every $24 \mathrm{~h}$ before their experimental use.

\subsection{Determination of $\beta$-galactosidase activity of lactobacilli}

The $\beta$-gal activity ( $\mathrm{U} \mathrm{mg}^{-1}$ protein) of LAB was assessed in cellfree extracts (CFE) obtained by mechanical disruption. The hydrolytic activity was determined with a colorimetric method $\left(\mathrm{OD}_{420}\right)$ that measures the hydrolysis rate of the synthetic substrate ONPG according to the experimental protocol described in our previous work. ${ }^{21}$ The transglycosidase activity of $\beta$-gal was determined qualitatively by TLC. Each CFE was mixed with $60 \%(\mathrm{w} / \mathrm{v})$ lactose $(1: 1)$ and incubated for $8 \mathrm{~h}$. Then a sample $(2 \mu \mathrm{L})$ containing $20 \mathrm{~g} \mathrm{~L}^{-1}$ sugar was spotted in TLC silica gel plates and eluted with a mixture of butanol, methanol and water in a 70:20:10 ratio as mobile phase. Detection was achieved visually by spraying with $5 \%$ sulfuric acid and $0.5 \% \alpha$-naphtol in ethanol and heating for $30 \mathrm{~min}$ at $100{ }^{\circ} \mathrm{C}$. Vivinal, glucose, lactose, raffinose and stachyose were used as standards.

\subsection{Synthesis of oligosaccharides from lactose (GOS) and lactulose (OsLu) by Lactobacillus bulgaricus CRL450}

The ability of Lactobacillus delbrueckii subsp. bulgaricus (hereinafter named as L. bulgaricus CRL450) to produce GOS and OsLu was studied according to the experimental protocol used in a previous work. ${ }^{21}$ The reaction mixtures, containing $\beta$-gal (1.3 $\mathrm{U} \mathrm{mL}^{-1}$ ) and the substrates (lactose or lactulose at $300 \mathrm{~g}$ $\mathrm{L}^{-1}$ ), were incubated at $45^{\circ} \mathrm{C}, \mathrm{pH} 6.5$, during $1,3,5,7,24 \mathrm{~h}$, and inactivated by heating. For comparison, Lactozym was used as control at the same conditions. All the samples were stored at $-20{ }^{\circ} \mathrm{C}$ until their corresponding analytical determinations. The reactions were conducted in duplicate, and each sample was analyzed twice.

\subsection{Partial purification of GOS}

The oligosaccharides synthesized by L. bulgaricus CRL450 (CRL450-GOS and CRL450-OsLu), Vivinal and Ao-OsLu were partially purified by selective adsorption onto activated charcoal to decrease their monosaccharide contents. ${ }^{32}$ One $\mathrm{mL}$ ( $\cong 300 \mathrm{mg}$ ) of carbohydrates and $3 \mathrm{~g}$ of activated charcoal (100-400 mesh) were mixed in $100 \mathrm{~mL}$ of $10 \%$ ethanol and stirred for $30 \mathrm{~min}$. The mixtures were filtered through Whatman No. 1 paper, and the charcoal was stirred with $100 \mathrm{~mL}$ of $50 \%$ ethanol for $30 \mathrm{~min}$ in order to remove the oligosaccharides. After a new filtration, the solution were evaporated under vacuum at $40^{\circ} \mathrm{C}$, dissolved in $1 \mathrm{~mL}$ of deionized water and stored at $-20{ }^{\circ} \mathrm{C}$. Prior to use, the purified GOS samples were analyzed by gas chromatography (GC-FID) to assess their carbohydrate contents.

\subsection{Growth of Lactobacillus bulgaricus CRL450 and probiotics on different oligosaccharides}

L. bulgaricus CRL450, L. casei CRL431, and B. animalis subsp. lactis BB-12 were cultured in MRS broth for $24 \mathrm{~h}$ at $37^{\circ} \mathrm{C}$ and $5 \% \mathrm{CO}_{2}$, harvested by centrifugation $(10000 \mathrm{~g}$ for $10 \mathrm{~min}$ at $4{ }^{\circ} \mathrm{C}$ ), washed twice and resuspended in sterile saline solution $(0.85 \%)$ to prepare carbon-free inoculum. These bacterial suspensions were inoculated at $2 \%(\mathrm{v} / \mathrm{v})$ (initial $\left.\mathrm{OD}_{600} \cong 0.1\right)$ in MRS which does not contain glucose and was supplemented with glucose, lactose, lactulose, not purified and purified oligosaccharides from Vivinal-GOS, Ao-OsLu, CRL450-GOS and CRL450-OsLu at a final concentration of $0.5 \%(\mathrm{w} / \mathrm{v})$. The growth in a medium without any carbon source was taken as negative control. The cultures were incubated at $37^{\circ} \mathrm{C}$ for $24 \mathrm{~h}$ and the growth was determined by the increase in the absorbance of bacterial biomass at $600 \mathrm{~nm}\left(\mathrm{OD}_{600}\right)$ in an automated microplate reader (Varioskan Flash). The maximum growth rate $\left(\mu_{\max }\right)$, maximum $\mathrm{OD}_{600}\left(\mathrm{OD}_{\max }\right)$ and lag parameter (lag) of strains were calculated by fitting the curves to a sigmoid model using the Microsoft Excel add-in DMfit v.3.5 (http://www.ifr.ac. uk/safety/DMfit/default.html). The bacterial counts (CFU mL ${ }^{-1}$ ), $\mathrm{pH}$ and lactic acid concentrations were determined at $0 \mathrm{~h}$, and $24 \mathrm{~h}$ for LAB and at $48 \mathrm{~h}$ for bifidobacteria. The colony forming units (CFU) were counted after plating ten-fold diluted samples on MRS agar that was incubated for $48 \mathrm{~h}$ at $37{ }^{\circ} \mathrm{C}$ under microaerophilic conditions ( $5 \% \mathrm{CO}_{2}$ atmosphere). The $\mathrm{pH}$-values were determined with a pHmeter Altronix TPXI and lactic acid was quantified by liquid chromatography (HPLC-RID).

\subsection{Determination of the prebiotic activity score (PAS) of CRL450-GOS and CRL450-OsLu}

The prebiotic potential was determined by the quantitative PAS based on the change in cell biomass after $24 \mathrm{~h}$ of growth of a probiotic strain on the prebiotic under study or glucose, relative to the biomass change of an enteric strain grown under the same conditions. ${ }^{33}$ With this aim, the growth of Escherichia coli C3 was assessed in the conditions described in section 2.6 for LAB and bifidobacteria. The PAS of Vivinal-GOS, Ao-OsLu, CRL450-GOS and CRL450-OsLu was calculated as:

$$
\mathrm{PAS}=\frac{\mathrm{PP}_{24}-\mathrm{PP}_{0}}{\mathrm{PG}_{24}-\mathrm{PG}_{0}}-\frac{\mathrm{EP}_{24}-\mathrm{EP}_{0}}{\mathrm{EG}_{24}-\mathrm{EG}_{0}}
$$

where $\mathrm{PP}_{24}$ and $\mathrm{PP}_{0}$ is the probiotic biomass $\left(\mathrm{OD}_{600}\right)$ on selected prebiotics after $24 \mathrm{~h}$ and $0 \mathrm{~h}$ of fermentation, respectively. $\mathrm{PG}_{24}$ and $\mathrm{PG}_{0}$ is the probiotic $\mathrm{OD}_{600}$ on glucose after $24 \mathrm{~h}$ and $0 \mathrm{~h}$ fermentation, respectively. $\mathrm{EP}_{24}, \mathrm{EP}_{0}$ and $\mathrm{EG}_{24}, \mathrm{EG}_{0}$ are the $E$. coli biomass on prebiotics and glucose after $24 \mathrm{~h}$ and $0 \mathrm{~h}$, respectively. Sugars concentration before and after fermentation was monitored by GC-FID.

\subsection{Chromatographic analysis of carbohydrates and organic acids}

2.8.1 HPLC with refractive index detection (RID). Carbohydrates and lactic acid were analyzed in a HPLC-RID system (Knauer, Germany) equipped with a Kromasil@ column 
$100-\mathrm{NH}_{2}(250 \mathrm{~mm} \times 4.6 \mathrm{~mm}, 5 \mu \mathrm{m}$ particle size, Akzo Nobel, Brewster, NY, USA). The elution was isocratic with a flow rate of $1 \mathrm{~mL} \mathrm{~min}^{-1}$ for $30 \mathrm{~min}$ using acetonitrile/water $(70: 30 \mathrm{v} / \mathrm{v})$ as mobile phase. For lactic acid analysis a Rezex ROA organic acids column $(300 \mathrm{~mm} \times 7.8 \mathrm{~mm}$ and $8 \mu \mathrm{m}$ particle size, Phenomenex Torrance, USA) was used and the separation was performed at $55{ }^{\circ} \mathrm{C}$ in an isocratic mode with $0.01 \mathrm{M} \mathrm{H}_{2} \mathrm{SO}_{4}$ as the mobile phase at a flow rate of $0.6 \mathrm{~mL} \mathrm{~min}^{-1}$. The data acquisition and processing were performed using EuroChrom for Windows Basic Edition v.3.05 software. The carbohydrates and lactic acid were identified by comparing their retention times $\left(t_{\mathrm{R}}\right)$ with those of standards and quantified by the external standard method, using calibration curves of each standard (0.05-5 $\left.\mathrm{mg} \mathrm{mL} \mathrm{mL}^{-1}\right){ }^{21}$ Carbohydrate standards included fructose and galactose for monosaccharides, lactose and lactulose for disaccharides, raffinose for trisaccharides and stachyose for tetrasaccharides quantification. The amounts of the different carbohydrates present in the mixtures were expressed as percentage of the total carbohydrate content. Lactic acid concentrations were reported as $\mathrm{mg} \mathrm{mL}^{-1}$ of grown culture medium. All HPLC analyses were performed in duplicate, obtaining relative standard deviation values below $10 \%$ in all cases.

2.8.2. Gas chromatography with flame ionization detector (GC-FID). The carbohydrates composition of (i) the reaction mixtures of L. bulgaricus CRL450 with lactose and lactulose at selected time, (ii) the unpurified and purified GOS and OsLu and (iii) the culture media supplemented with the purified GOS or OsLu (0 and $24 \mathrm{~h}$ ) after the growth of L. bulgaricus CRL450 and probiotics, were determined by GC-FID as described previously. ${ }^{21}$ The carbohydrates were analyzed as trimethyl silylated oximes (TMSO) in an Agilent Technologies 7890A Gas Chromatograph (Wilmington, DE, USA) equipped with a commercial fused silica capillary column DB-5HT, bonded, crosslinked phase $(30 \mathrm{~m} \times 0.25 \mathrm{~mm}$ i.d. and $0.25 \mu \mathrm{m}$ film thickness, J\&W Scientific, Folson, California, USA). The oven temperature was initially $180{ }^{\circ} \mathrm{C}$ increased at a rate of $3{ }^{\circ} \mathrm{C} \min ^{-1}$ to $350{ }^{\circ} \mathrm{C}$ and then held for $25 \mathrm{~min}$. The injector and detector temperatures were set at 280 and $355{ }^{\circ} \mathrm{C}$, respectively. The injections were conducted in split mode $(1: 20)$ using nitrogen at $1 \mathrm{~mL}$ $\mathrm{min}^{-1}$ as the carrier gas. The data acquisition and integration were done using Agilent ChemStation Rev. B.03.01 software.

\subsection{Statistical analysis}

All analyses were carried out at least in duplicate and the data were expressed as mean \pm SD. The one-way analysis of variance (ANOVA) and Tukey's test $(p<0.05)$ were applied to all of the assays. In addition, Pearson correlation coefficient was calculated for all the variables. All statistical analyses were performed on R v3.5.0.

\section{Results and discussion}

\subsection{Determination of $\beta$-galactosidase activity of lactobacilli}

In recent years, functional foods containing probiotics and prebiotics have gained a lot of attention from the food indus- try. LAB are the most frequently used probiotics, whereas GOS are well-recognized prebiotics. Therefore, it was in our interest to study the ability of potential probiotics to produce prebiotics. With this aim, we screened the hydrolytic and transglycosidase $\beta$-gal activity of Argentinian lactobacilli strains isolated from different origins.

To evaluate hydrolytic activity, 20 Lactobacillus strains belonging to the culture collection of CERELA-CONICET were inoculated into a basic broth containing lactose as the sole carbon source (L. plantarum, $n=8 ;$ L. paracasei, $n=4$; L. bulgaricus, $n=4$; L. reuteri, $n=1$; L. fermentum, $n=1$; L. sakei, $n=1$; L. acidophilus, $n=1$ ) (Table 1 ). Most of the strains (15 out of 20 ) expressed $\beta$-gal activity and were able to develop at the expense of lactose. Although the growth varied among the strains, the highest biomasses were achieved by L. paracasei CRL 200 ( $\mathrm{OD}_{600} \max$ : 0.99), significantly higher than those reported for the rest of the strains. However, L. bulgaricus strains showed the highest specific enzyme activity determined in CFE by the hydrolysis of ONPG, especially $(p<0.05)$ L. bulgaricus CRL450 (2.06 $\left.\mathrm{U} \mathrm{mg}^{-1}\right)$. A wide range of kinetics of hydrolysis was observed among lactobacilli, and L. bulgaricus CRL450 showed the significantly highest slope (Table 1 and Fig. S1 of the ESI $\dagger$ ). These results suggest that $\beta$-gal activity does not significantly depend on the species but on the strain. On the other hand, $\beta$-gal activity was independent of $\mathrm{OD}_{600}$ values. Thus, in general, the maximum growth rates of $L$. paracasei were significantly higher than those of L. bulgaricus. In addition, no significant differences in the $\mathrm{pH}$ or enzymatic activity were observed according to the species and origin of the microorganism, while those strains isolated from cabbage and cheese showed significantly higher $\mathrm{OD}_{600}$ values than those isolated from yoghurt and pea. In summary, no relevant correlations could be found between $\mathrm{OD}_{600}, \mathrm{pH}$ and $\beta$-galactosidase activity. Regarding trangalactosylation capability, the reaction mixtures of 11 strains showed sugars that appeared in the TLC chromatogram at the position corresponding to oligosaccharides when compared to commercial Vivinal used as standard (Fig. S2 $\dagger$ ).

At present, most of the GOS-containing products commercially available are manufactured with the fungal enzymes of $A$. oryzae or $K$. lactis or the bacteria $B$. circulans. ${ }^{6}$ However, depending on the source of $\beta$-gal and the reaction conditions, the amounts of GOS obtained, the monomer composition and the linkages between D-galactose units may vary, affecting their prebiotic potential. ${ }^{6,34,35}$ In this regard, it has been proposed that $\beta$-gal from probiotic microorganisms would be more appropriate for the production of selective prebiotic oligosaccharides. ${ }^{24,31}$ Since L. bulgaricus CRL450 displayed the highest hydrolytic activity and also transglycosidase capacity, it was selected to further study its ability to synthesize GOS and OsLu using lactose and lactulose as substrates, respectively.

\subsection{Synthesis of oligosaccharides from lactose and lactulose}

Fig. 1 shows the enzymatic synthesis of galactosyl derivatives from lactose and lactulose, respectively, using the $\beta$-gal of L. bulgaricus CRL450 (CRL450- $\beta$-gal) and Lactozym as a refer- 


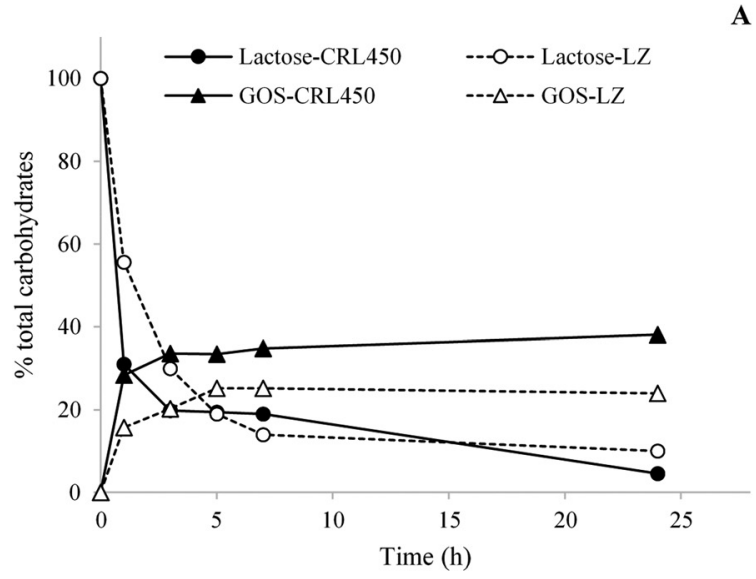

A
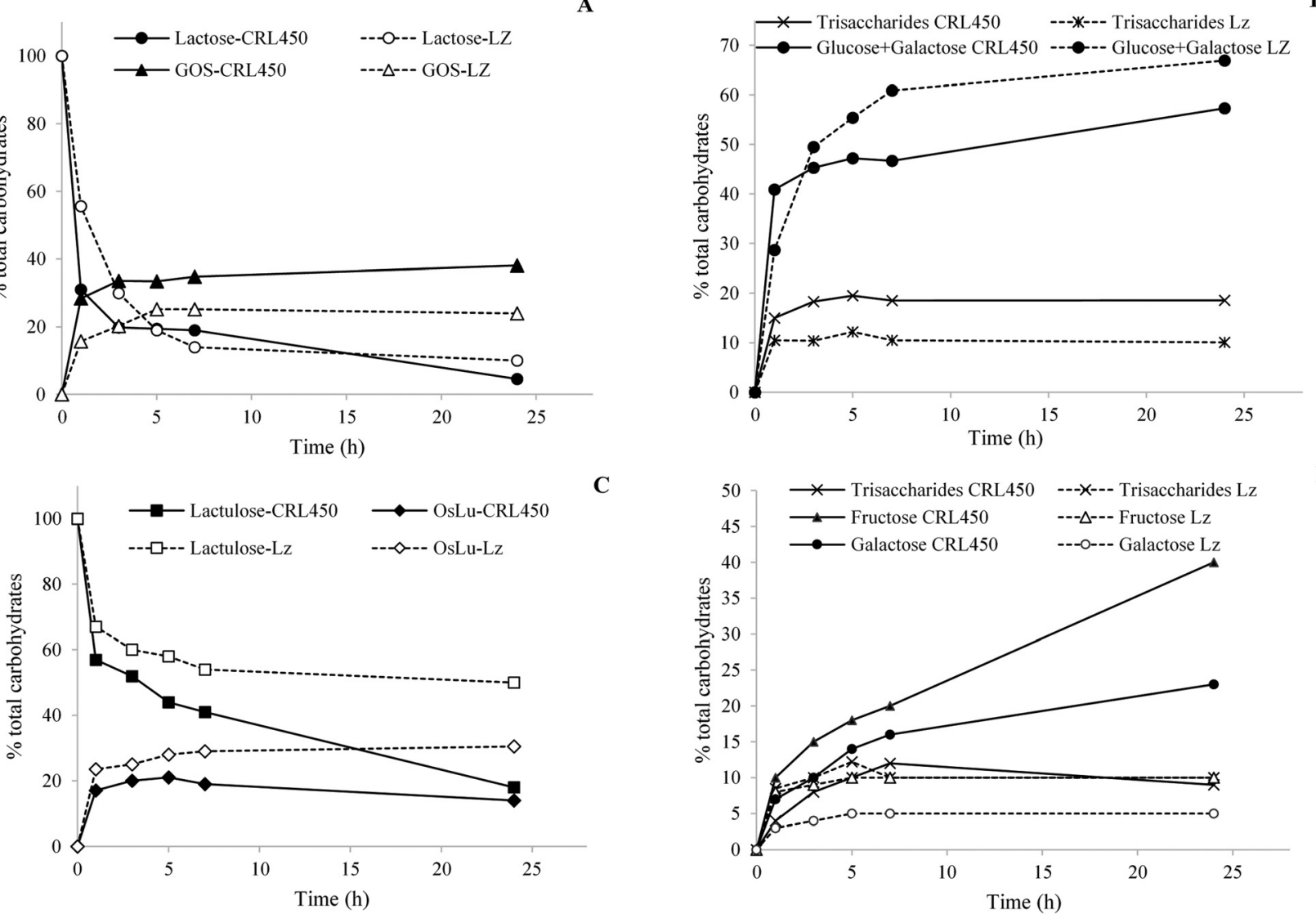

C

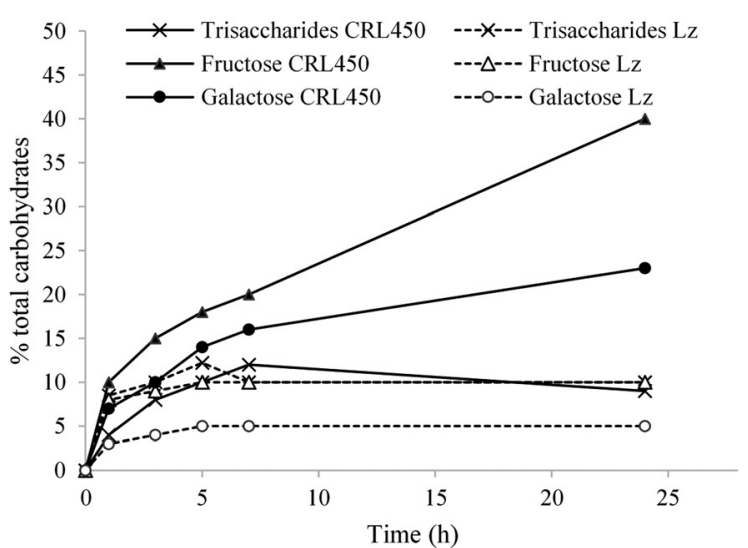

D

Fig. 1 Time course of reactions catalyzed with $\beta$-galactosidase of Lactobacillus bulgaricus CRL 450 and Lactozym Pure $6500 \mathrm{~L}$ (Lz) at $45^{\circ} \mathrm{C}$, pH 6.5 and $300 \mathrm{~g} \mathrm{~L}^{-1}$ of lactose as substrate: (A) lactose and galacto-oligosaccharides (GOS) (B) mono- and trisaccharides, or $300 \mathrm{~g} \mathrm{~L}^{-1}$ of lactulose as substrate: (C) lactulose and oligosaccharides derived from lactulose (OsLu) (D) mono- and trisaccharides. Carbohydrates in reaction mixtures were quantified by HPLC-RID.

ence. The time course of lactose hydrolysis and GOS synthesis showed a rapid decrease in the lactose concentration in the first $3 \mathrm{~h}$ of reaction with both enzymes, being significantly faster with CRL450- $\beta$-gal. After $24 \mathrm{~h}$ of reaction, the degradation of $95.4 \%$ and $90.0 \%$ of lactose (w/w, with respect to total sugars) was achieved with CRL450- $\beta$-gal and Lactozym, respectively showing no significant differences among them (Fig. 1A). Although a lower amount of lactose remains with the unpurified extract containing $\beta$-gal of lactobacilli, Lactozym was more hydrolytic, releasing significantly higher amounts of monosaccharides (66.9\% vs. $57.3 \%$ at 24 h) (Fig. 1B). Regarding transgalactosylation, in correlation to hydrolytic activities, the CRL450- $\beta$-gal was more active than Lactozym after $3 \mathrm{~h}$ of reaction, reaching $33.6 \%$ of oligosaccharides $v s$. $20.3 \%$ synthesized by Lactozym. Maximum GOS formation by CRL450- $\beta$-gal was achieved after $24 \mathrm{~h}$ (38.1\%, with $18.6 \%$ corresponding to trisaccharides), whereas only $24 \%$ of GOS were obtained with Lactozym (Fig. 1A).

When lactulose was used as the substrate, an opposite pattern was observed: CRL450- $\beta$-gal was more hydrolytic than Lactozym and released significantly higher amounts of galactose and fructose, whereas Lactozym displayed significantly higher transgalactosidase activity and synthesized more OsLu (Fig. 1C and D). Maximum production of OsLu by Lactozym was attained after $24 \mathrm{~h}$ of reaction and corresponded to $30.5 \%$ of total carbohydrates, whereas a maximum of $21.0 \%$ OsLu was obtained with CRL450- $\beta$-gal at $5 \mathrm{~h}$ (Fig. 1C). Finally, although a similar hydrolysis of both substrates was observed with CRL450- $\beta$-gal, a significantly larger amount of oligosaccharides was obtained from lactose.

In order to elucidate the composition of the oligosaccharide mixtures synthesized from lactose and lactulose by the CRL450- $\beta$-gal, the samples obtained at the time of maximum production were analyzed by GC-FID and compared with the profile of oligosaccharides found in the reaction mixtures performed with Lactozym. Fig. 2a shows the presence of mono-, di-, and trisaccharides that were compared with oligosaccharides previously synthesized by our research group ${ }^{15,16,36}$ and the commercial GOS product Bimuno®. Among the oligosaccharides obtained from lactose, the following could be mentioned: the disaccharides allolactose $(\beta$-D-Gal $p-(1 \rightarrow 6)$-D-Glu $)$ (peak 7$)$ and 6-galactobiose $(\beta-\mathrm{D}-\mathrm{Gal} p-(1 \rightarrow 6)$-D-Gal) (peak 9), the trisaccharides $6^{\prime}$-galactosyl-lactose $(\beta$-D-Gal $p-(1 \rightarrow 6)$ lactose) (peak 10), and 3 '-galactosyl-lactose ( $\beta$-D-Gal $p-(1 \rightarrow 3)$ - 


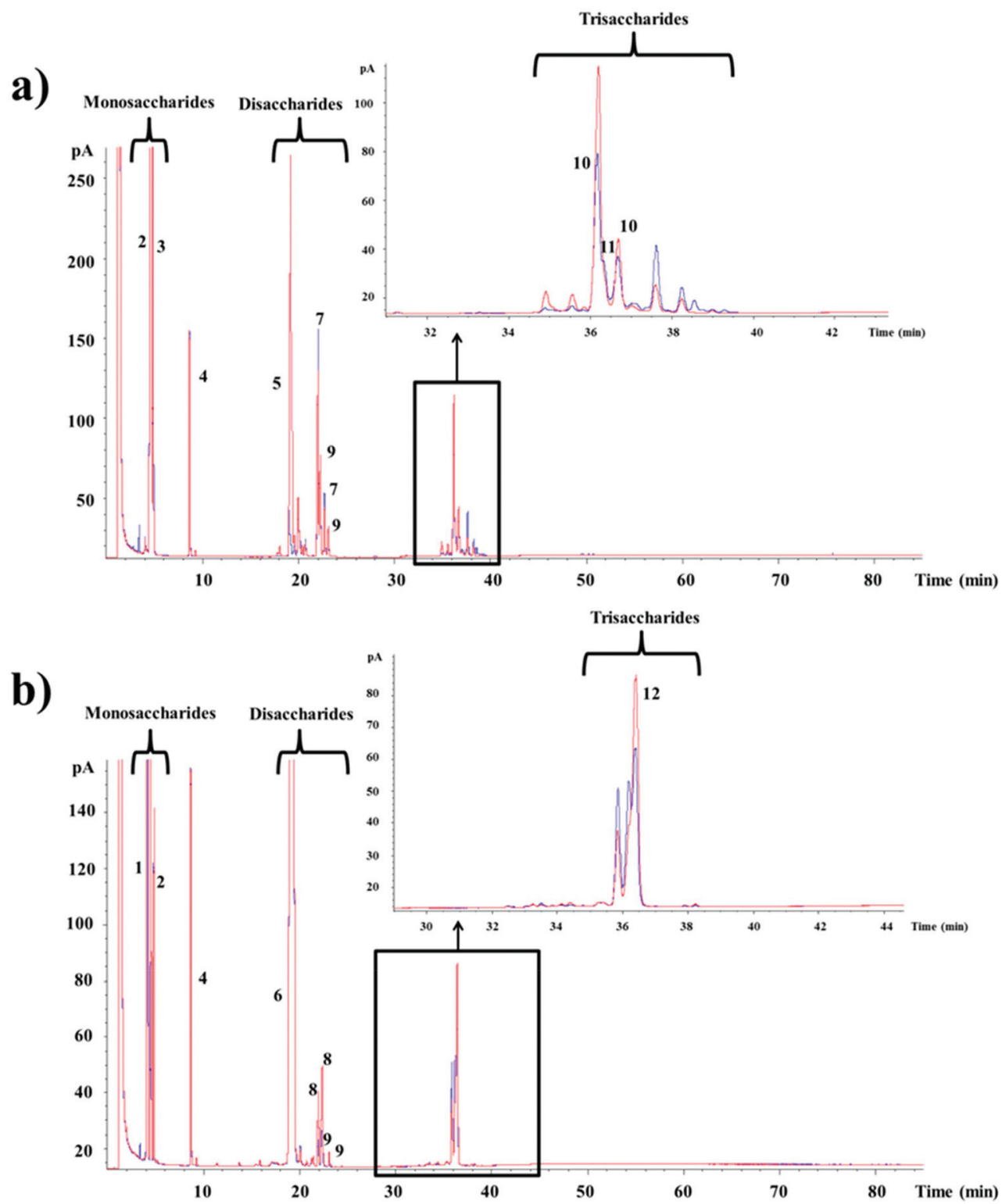

Fig. 2 Gas chromatographic (GC-FID) profile of the carbohydrates present in the reaction mixtures of $\beta$-galactosidase (1.3 $\mathrm{U} \mathrm{mL}^{-1}$ ) from Lactobacillus bulgaricus CRL 450 (blue line) with $300 \mathrm{~g} \mathrm{~L}^{-1}$ of (a) lactose or (b) lactulose performed at $45^{\circ} \mathrm{C}, \mathrm{pH} 6.5 \mathrm{during} 7 \mathrm{~h}, \mathrm{compared}$ with the obtained with Lactozym (red line). 1: fructose, 2: galactose, 3: glucose, 4: internal standard, 5: lactose, 6: lactulose, 7: allolactose, 8: allolactulose, 9: 6-galactobiose, 10: 6'-galactosyl lactose, 11: 3'-galactosyl lactose, 12: 6'-galactosyl lactulose.

lactose) (peak 11). Commercial GOS products are mixtures of monosaccharides, disaccharides and trisaccharides with different linkages: Vivinal and Oligomate ${ }^{\circledR}$ contain predominantly $\beta-(1 \rightarrow 4)$ trisaccharides. ${ }^{31,37}$ In the case of potential probiotic bacteria, it has been reported that bifidobacteria such as B. bifidum NCIMB 41171 synthesize GOS formed mainly with $\beta-(1 \rightarrow 3)$ linkages, ${ }^{38}$ P. acidipropionici LET 120 produces GOS $\beta(1 \rightarrow 6), \beta(1 \rightarrow 3)$ and $\beta(1 \rightarrow 4)$ linked trisaccharides, ${ }^{21}$ whereas other Lactobacillus species have been shown to produce $\beta-(1 \rightarrow 6)$ and $\beta-(1 \rightarrow 3)$ linkages in their transgalactosylation mode. ${ }^{25,29,39}$ This property is relevant since we have recently studied the digestibility of these compounds using brush border membrane vesicles from pig small intestine and found that $\beta(1 \rightarrow 6)$ linkage had higher resistance than $\beta(1 \rightarrow$ $4)$ and $\beta(1 \rightarrow 3)$ linkages. ${ }^{40}$ Therefore, the new synthetized GOS could be expected to reach the gut in large quantities.

Regarding the oligosaccharides formed from lactulose with the CRL450- $\beta$-gal (Fig. 2 b), the di- and trisaccharides identified by comparison with OsLu synthesized by our research group ${ }^{16}$ were allolactulose $(\beta$-D-Gal $p$ - $(1 \rightarrow 6)$-D-Fru) (peaks 8$), 6$-galactobiose (peaks 9) and 6'-galactosyl-lactulose $(\beta$-D-Gal $p$ - $(1 \rightarrow 6)$-lactulose) (peak 12). Other trisaccharides and tetrasaccharides that were also detected could not be identified. This type of oligosaccharides has been studied using the $\beta$-gal from fungi such as $K$. lactis, A. oryzae, and A. aculeatus. ${ }^{12,16,17,35}$ Regarding bacteria, we previously reported the synthesis of $26.1 \%$ OsLu 
containing mainly $\beta(1 \rightarrow 6)$ linked trisaccharides using $\beta$-gal of P. acidipropionici LET $120,{ }^{21}$ while $\beta$-gal from $B$. circulans was not able to hydrolyze the lactulose. As far as we know, this is the first report about the synthesis of lactulose-derived oligosaccharides with Lactobacillus $\beta$-gal. It should be noted that intestinal bacteria and probiotics belonging to Bifidobacterium and Lactobacillus spp. have shown the ability to use the trisaccharides derived from lactulose and lactose, but with a general preference towards $\beta(1 \rightarrow 6)$ and $\beta(1 \rightarrow 3)$ over $\beta(1 \rightarrow 4)$ linked products. $^{35,39,41}$ Then, it could be expected that CRL450-GOS/ OsLu could exhibit good prebiotic potential.

Table 2 shows the concentration of oligosaccharides (di-, tri- and tetrasaccharides) obtained with CRL450- $\beta$-gal from both substrates. In the reaction mixtures containing lactose, the major disaccharide was allolactose $(7.7 \%)$ and the main trisaccharides were 6'-galactosyl-lactose (11.2\%) and 3'-galactosyllactose (7.1\%). Unknown di-, tri- and tetrasaccharides were also quantified and all of them were included in GOS values. In the hydrolysates from lactulose, similarly the main di- and trisaccharides were allolactulose (2.4\%) and 6'-galactosyl-lactulose $(9.8 \%)$. Unknown di- and trisaccharides were included in OsLu values. The total amounts (as percentage of total sugars) of GOS and OsLu obtained with the unpurified CRL450- $\beta$-gal were $41.3 \%$ and $21.0 \%$, respectively. GOS yield is in the same range of values ( 26.8 to $41 \%$ ) reached with other LAB such as L. reuteri, ${ }^{25}$ L. acidophilus ${ }^{26}$ and L. plantarum $^{29}$ and within the more typical optimized GOS yields of around 30 to $40 \% .^{42}$ Regarding L. bulgaricus, it has been reported that GOS yield by

Table 2 Carbohydrate content (\% of total carbohydrates in the sample) determined by GC-FID, found in the reaction mixtures with $300 \mathrm{~g} \mathrm{~L}^{-1}$ of lactose or lactulose incubated at $45^{\circ} \mathrm{C}$ and $\mathrm{pH} 6.5$ with $\beta$-galactosidase of $L$. bulgaricus CRL450 at maximum oligosaccharide formation times $(5 \mathrm{~h})$. Values are mean $( \pm S D)$

\begin{tabular}{lll}
\hline & GOS-CRL450 & OsLu-CRL450 \\
\hline Fructose & - & $16.92(0.39)$ \\
Galactose & $7.12(0.24)$ & $9.32(0.20)$ \\
Glucose & $15.62(0.86)$ & - \\
Lactose & $35.96(2.28)$ & - \\
Lactulose & - & $52.23(2.14)$ \\
Allolactose & $7.67(0.57)$ & - \\
Allolactulose & - & $2.39(0.14)$ \\
6-Galactobiose & $0.93(0.06)$ & $0.93(0.22)$ \\
Others Di-GOS & $4.22(0.06)$ & $2.07(0.08)$ \\
6'GaLa $^{\prime}$ & $11.20(0.00)$ & - \\
3'GaLa $^{\prime}$ GaLu & $7.14(0.16)$ & - \\
Others Tri-GOS & - & $9.75(1.08)$ \\
& $7.25(0.32)$ & $4.82(1.13)$ \\
Monosaccharides & & $26.76(0.61)$ \\
Disaccharides & $22.74(1.10)$ & $57.62(2.15)$ \\
Trisaccharides & $48.78(1.58)$ & $14.57(0.06)$ \\
Tetrasaccharides & $25.58(0.17)$ & $1.05(1.48)$ \\
GOS $^{a}$ & $2.90(0.31)$ & $\mathbf{2 1 . 0 0}(\mathbf{1 . 5 3})$ \\
OsLu $^{b}$ & $\mathbf{4 1 . 3 0 ( 0 . 1 8 )}$ &
\end{tabular}

${ }^{a}$ GOS: $\sum$ Allolactose, 6-galactobiose; 3'galactoyl-lactose (3'GaLa); 6' galactoyl-lactose (6'GaLa); unknown di-, tri- and tetrasaccharides. ${ }^{b}$ OsLu: $\sum$ Allolactulose, 6-galactobiose; 6'galactoyl-lactulose (6' $\left.\mathrm{GaLu}\right)$; unknown di-, tri- and tetrasaccharides.
L. bulgaricus L3 was increased by cloning the $\beta$-gal gene (bgaL3) and fusing with cellulose-binding domain using pET-35b(+) vector in $E$. coli. The resulting fusion protein was immobilized onto microcrystalline cellulose to produce up to $49 \%$ GOS. ${ }^{30}$ Although these results were promising, the use of genetically engineered enzymes for food remains a concern in many countries.

\subsection{Growth of L. bulgaricus CRL450 on prebiotic oligosaccharides}

Prebiotics are mainly targeted to enhance the growth of beneficial bacteria such as bifidobacteria in the gut or alternatively in a symbiotic product. ${ }^{41}$ Therefore, tailor-made GOS produced by lactobacilli- $\beta$-gal could be advantageous also for their own proliferation. Then, we tested the ability of L. bulgaricus CRL450 to develop at the expense of different carbohydrates that include no prebiotics (glucose and lactose), prebiotics (lactulose, Vivinal and $A o-O s L u$ ) and potential prebiotics (CRL450-GOS and CRL450-OsLu). As negative control the growth in the absence of carbon sources was included for comparison. Fig. 3 shows the kinetics of growth on the different carbon sources whereas Table 3 presents some relevant parameters in the conditions assayed.

As expected, no growth was observed in the absence of a carbohydrate source but $L$ bulgaricus CRL450 was able to grow to different extents in all the substrates tested. $\mathrm{OD}_{600}$ values for CRL450-OsLu and CRL450-GOS were significantly higher than those obtained for lactulose and Ao-OsLu (Fig. 3). Maximum growth was obtained in the oligosaccharides synthesized by their own $\beta$-gal, although these substrates also produced the longer lag phase (Fig. 3 and Table 3). Other studies have also reported that Bifidobacterium and Propionibacterium strains preferably ferment GOS over lactose and more simple carbohydrates like glucose or galactose. ${ }^{21,43-45}$ After $12 \mathrm{~h}$ of incubation, L. bulgaricus CRL450 reached the stationary phase in all the substrates tested except in CRL450-OsLu, showing at

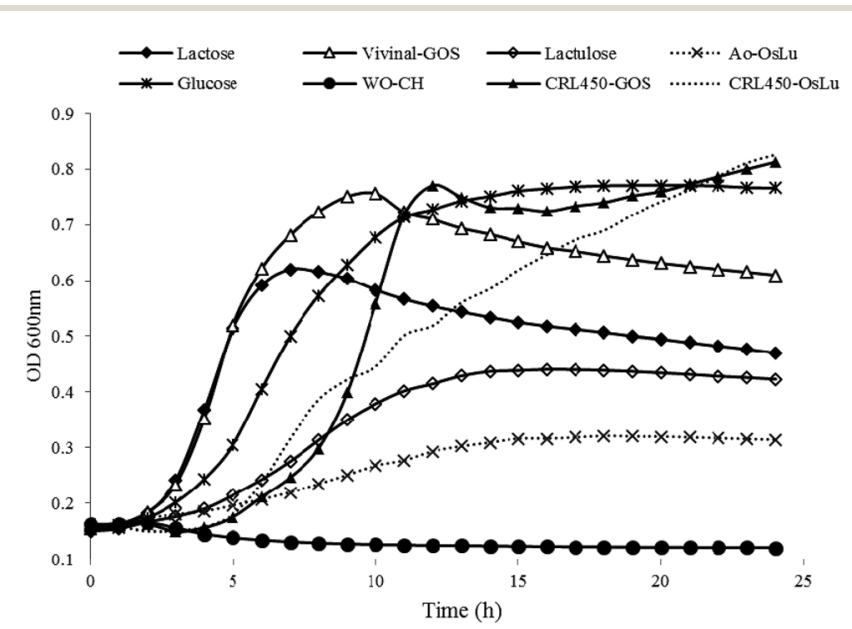

Fig. 3 Growth curves of Lactobacillus bulgaricus CRL 450 at expense of different carbohydrates at $0.5 \%(\mathrm{w} / \mathrm{v})$ final concentration. Each curve is the average of two independent assays. 
Table 3 Some relevant parameters related to growth of $L$. bulgaricus CRL450 at expense of different carbon sources. Data are means of two independent assays $( \pm \mathrm{SD})$

\begin{tabular}{|c|c|c|c|c|c|c|c|c|}
\hline Growth parameters & Glucose & Lactose & Lactulose & Vivinal & $A o$-OsLu & CRL450 GOS & CRL450 OsLu & No sugar \\
\hline Lag $(\mathrm{h})$ & $2.83 \pm 0.07^{\mathrm{d}}$ & $2.53 \pm 0.02^{\mathrm{d}}$ & $3.36 \pm 0.18^{\mathrm{c}}$ & $2.49 \pm 0.02^{\mathrm{d}}$ & $2.95 \pm 0.29^{\mathrm{c}, \mathrm{d}}$ & $7.32 \pm 0.12^{\mathrm{a}}$ & $4.16 \pm 0.21^{\mathrm{b}}$ & - \\
\hline Final $\mathrm{pH}^{b}$ & $4.17 \pm 0.11^{\mathrm{c}, \mathrm{d}}$ & $4.43 \pm 0.10^{\mathrm{b}, \mathrm{c}, \mathrm{d}}$ & $4.69 \pm 0.08^{\mathrm{b}}$ & $4.05 \pm 0.03^{\mathrm{d}}$ & $4.51 \pm 0.15^{\mathrm{b}, \mathrm{c}}$ & $4.30 \pm 0.03^{\mathrm{b}, \mathrm{c}, \mathrm{d}}$ & $4.34 \pm 0.04^{\mathrm{b}, \mathrm{c}, \mathrm{d}}$ & $6.33 \pm 0.02^{\mathrm{a}}$ \\
\hline$\mu\left(\mathrm{h}^{-1}\right)$ & $0.079 \pm 0.001^{\mathrm{b}}$ & $0.134 \pm 0.014^{\mathrm{a}}$ & $0.034 \pm 0.001^{\mathrm{b}, \mathrm{c}}$ & $0.145 \pm 0.014^{\mathrm{a}}$ & $0.015 \pm 0.000^{\mathrm{c}}$ & $0.151 \pm 0.016^{\mathrm{a}}$ & $0.056 \pm 0.040^{\mathrm{b}, \mathrm{c}}$ & - \\
\hline$\beta-\mathrm{Gal}\left(\mathrm{U} \mathrm{mg}^{-1}\right)$ & $0.89 \pm 0.03^{\mathrm{d}}$ & $2.06 \pm 0.03^{\mathrm{a}, \mathrm{b}}$ & $1.04 \pm 0.21^{\mathrm{d}}$ & $1.71 \pm 0.10^{\mathrm{b}, \mathrm{c}}$ & $1.97 \pm 0.13^{\mathrm{a}, \mathrm{b}}$ & $1.51 \pm 0.15^{\mathrm{c}}$ & $2.19 \pm 0.02^{\mathrm{a}}$ & $0.90 \pm 0.00^{\mathrm{d}}$ \\
\hline
\end{tabular}

$24 \mathrm{~h} \mathrm{OD}_{600 \mathrm{~nm}}$ of 0.83 . The significantly highest $(p<0.05) \mu_{\max }$ were attained with CRL450-GOS and Vivinal used as carbon sources. On the contrary, lower growth rates and biomasses were obtained on lactulose and $A o-O s L u$, reaching $\mathrm{OD}_{600}$ of 0.43 and 0.31 for each substrate, respectively, being $\mathrm{OD}_{600}$ values for $A o$-OsLu significantly lower than in other conditions $(p<0.05)$. Statistically significant differences were found between the studied substrates when the lag times, growth rates and maximum CFU, were also calculated (Table 3). In this case, when the growth of L. bulgaricus CRL 450 was evaluated at the expense of different carbon sources, final $\mathrm{pH}$ was correlated to Log CFU $\mathrm{mL}^{-1}$ and lactic acid production while $\mathrm{OD}_{600}$ and $\mu_{\max }$ were most strongly correlated. In agreement with the absorbance data, no $\mathrm{pH}$ change was detected in the negative control, while a significant $\mathrm{pH}$ decrease of 1.57 to 2.62 units was observed in all of the other samples after $24 \mathrm{~h}$. Lactic acid production was significantly higher in cultures grown on disaccharides and oligosaccharides than in a pure monosaccharide like glucose. Regarding $\beta$-gal, L. bulgaricus CRL450 displayed enzyme activity in the absence of carbon sources and the presence of glucose, suggesting a constitutive basal level of $\beta$-gal, but also the induction of synthesis by their specific substrates, showing the highest activity when CRL450 was grown at the expense of lactose and lactulose-derived oligosaccharides (Table 3).

However, it should be noted that these data correspond to the growth of L. bulgaricus CRL450 on mixtures of oligosaccharides that also contain monosaccharides; therefore, we considered it relevant to study the performance of the strain on purified oligosaccharides. At $24 \mathrm{~h}$ of incubation of CRL450 with the purified substrates, the increase on bacterial biomass was negligible (less than 0.1 at $\mathrm{OD}_{600}$ ); however, the decrease of $\mathrm{pH}$ of around 1.5 units (from 6.5 to 5.1) and the appearance of lactic acid in the culture media (1.18 to $1.45 \mathrm{mg} \mathrm{mL} \mathrm{mL}^{-1}$ ) suggest metabolic activity of the microorganisms at the expense of these substrates (Table $\mathrm{S} 1 \dagger$ ). In relation to growth of $L$. bulgaricus CRL 450 with purified oligosaccharides, $\mathrm{OD}_{600}$ values for CRL450-GOS were significantly higher than those for Vivinal while CRL450-GOS and CRL450-OsLu showed significantly lower final $\mathrm{pH}$ values. No relevant differences were observed with regard to lactic acid production.

\subsection{Determination of the prebiotic capacity of CRL450-GOS and CRL450-OsLu on the producer strain and probiotic cultures}

As mentioned, prebiotic candidates should be able to stimulate the growth of intestinal bifidobacteria and lactobacilli. ${ }^{41} \mathrm{~A}$ first step to test the prebiotic properties of the new GOS was to perform assays with pure cultures of recognized probiotics of intestinal origin. With this aim, B. animalis subsp. lactis BB-12 and L. casei CRL431 were inoculated in media containing glucose, or the not purified and purified Vivinal, Ao-OsLu, CRL450-GOS and CRL450-OsLu as the sole carbohydrate source. The growth of the strains was evaluated by bacterial biomass absorbance and $\mathrm{pH}$ determination at $24 \mathrm{~h}$ (Table 4). To have a prebiotic activity, the studied sugar should be metabolized by the test strain preferably better than glucose.

Both probiotics were able to develop on GOS and OsLu in spite of their microbial origin and purity, as evidenced by the increase in $\mathrm{OD}_{600}$ and the decrease in the $\mathrm{pH}$ of media (Table 4). Interestingly, the increase of biomass of both lactobacilli, CRL431 and CRL450 were strongly correlated. When the prebiotic index (PAS) was determined using as substrates the oligosaccharide mixtures without purification, a positive score was observed for all the strains and conditions tested (Fig. 4). This was due to the strong growth of LAB and bifidobacteria and the poor development of E. coli on all the oligosaccharides tested. L. casei CRL431 showed high growth rates on all oligosaccharides while $B$. animalis BB-12 and L. bulgaricus CRL450 grew significantly better on Vivinal-GOS than in the other substrates. The lowest growth rates were observed for L. bulgaricus CRL450 on Ao-OsLu and for B. animalis BB-12 on CRL450-GOS compared to the other studied strains (Fig. 4a).

When the prebiotic effect of the purified oligosaccharides was analyzed, it was observed that L. casei CRL431 and especially L. bulgaricus CRL450 showed poor growths (Table 4) and, therefore, their prebiotic scores were negative (Fig. 4b). However, $B$. animalis BB-12 still showed significantly good growths over purified Ao-OsLu, CRL450-GOS and CRL450-OsLu $(p<0.5)$.

These results showed a low growth of $L$. bulgaricus CRL450 on the oligosaccharides produced by the strain, contrary to 
Table 4 Increase in the cell density between time 0 and time $24 \mathrm{~h}$ and final $\mathrm{pH}$ for pure cultures of selected probiotic strains grown on various oligosaccharide substrates not purified and purified

\begin{tabular}{|c|c|c|c|c|c|c|}
\hline & \multicolumn{2}{|c|}{ Lactobacillus casei CRL431 } & \multicolumn{2}{|c|}{$\begin{array}{l}\text { Bifidobacterium animalis subsp. lactis } \\
\text { BB-12 }\end{array}$} & \multicolumn{2}{|c|}{ Lactobacillus bulgaricus CRL450 } \\
\hline & Increase of biomass ${ }^{a}$ & Final $\mathrm{pH}^{b}$ & Increase of biomass ${ }^{a}$ & Final $\mathrm{pH}^{b}$ & Increase of biomass ${ }^{a}$ & Final $\mathrm{pH}^{a}$ \\
\hline Vivinal GOS & $0.77 \pm 0.07^{\mathrm{b}}$ & $3.80 \pm 0.06^{\mathrm{d}}$ & $0.81 \pm 0.04^{\mathrm{a}}$ & $5.76 \pm 0.08^{\mathrm{a}, \mathrm{b}}$ & $0.55 \pm 0.03^{\mathrm{a}}$ & $5.61 \pm 0.07^{\mathrm{a}}$ \\
\hline$A o$-OsLu & $0.84 \pm 0.05^{\mathrm{b}}$ & $3.82 \pm 0.03^{\mathrm{d}}$ & $0.61 \pm 0.02^{\mathrm{b}, \mathrm{c}}$ & $5.82 \pm 0.08^{\mathrm{a}}$ & $0.21 \pm 0.00^{\mathrm{b}, \mathrm{c}}$ & $5.51 \pm 0.03^{\mathrm{a}}$ \\
\hline CRL450-GOS & $1.03 \pm 0.03^{\mathrm{a}}$ & $4.10 \pm 0.03^{\mathrm{c}}$ & $0.50 \pm 0.11^{\mathrm{c}}$ & $4.51 \pm 0.16^{\mathrm{e}}$ & $0.66 \pm 0.05^{\mathrm{a}}$ & $4.30 \pm 0.03^{\mathrm{c}}$ \\
\hline Purified CRL450-GOS & $0.32 \pm 0.05^{\mathrm{d}, \mathrm{e}}$ & $4.52 \pm 0.00^{\mathrm{b}}$ & $0.63 \pm 0.05^{\mathrm{b}, \mathrm{c}}$ & $5.07 \pm 0.10^{\mathrm{d}}$ & $0.02 \pm 0.02^{\mathrm{c}}$ & $5.03 \pm 0.02^{\mathrm{b}}$ \\
\hline Purified CRL450-OsLu & $0.41 \pm 0.02^{\mathrm{d}}$ & $4.28 \pm 0.08^{\mathrm{c}}$ & $0.63 \pm 0.04^{\mathrm{b}, \mathrm{c}}$ & $5.32 \pm 0.19^{\mathrm{b}, \mathrm{c}, \mathrm{d}}$ & $0.02 \pm 0.01^{\mathrm{c}}$ & $5.19 \pm 0.03^{b}$ \\
\hline
\end{tabular}

${ }^{a}$ Determination of biomass in pure cultures was done by turbidimetry and reported as $\mathrm{OD}_{600 .}{ }^{b}$ Culture medium $\mathrm{pH}$ at the end of fermentation of probiotics with different carbohydrates as the only carbon source. Initial pH was $6.50 \pm 0.11$. ${ }^{\mathrm{a}, \mathrm{b}, \mathrm{c}, \mathrm{d}, \mathrm{e}, \mathrm{f}}$ Statistically significant differences between groups.
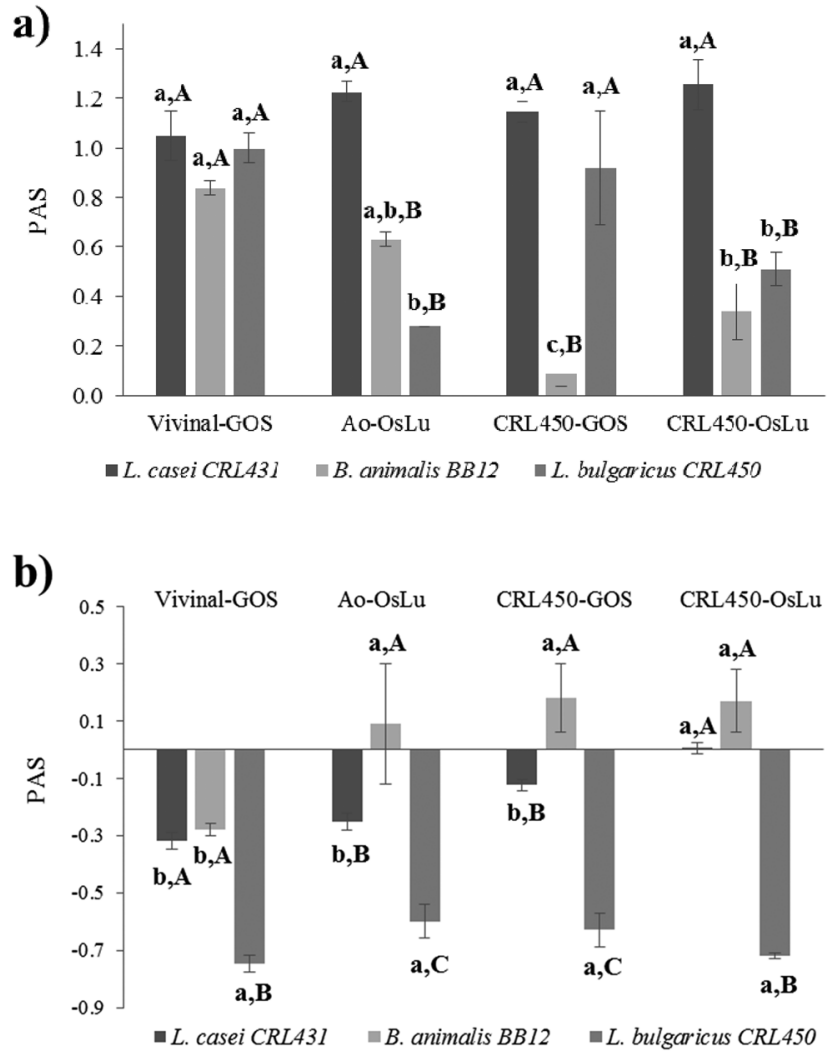

Fig. 4 Prebiotic activity scores (PAS) of oligosaccharides not purified (panel a) and purified (panel b) on selected probiotics and L. bulgaricus CRL 450. a, b, c Statistically significant differences among carbon sources. ${ }^{\text {A }, ~ B, ~ C ~ S t a t i s t i c a l l y ~ s i g n i f i c a n t ~ d i f f e r e n c e s ~ b e t w e e n ~ s t r a i n s . ~}$

expectations, since it is assumed that oligosaccharides produced by probiotics may exert better prebiotic properties. ${ }^{31}$ To determine the extent of the metabolic activity of bacteria when they grow at the expense of the different purified oligosaccharides, carbohydrate consumption was analyzed after $24 \mathrm{~h}$ of fer- mentation. Table 5 shows the use of the substrates by the probiotics and L. bulgaricus CRL450. Consumption of total carbohydrates was evidenced in all cases, ranging from $79 \%$ for L. casei CRL431 with CRL450-GOS and $38 \%$ to B. animalis BB12 with the same substrate. In this respect, $L$. casei CRL 431 was the most metabolically active microorganism with the highest consumption of GOS and OsLu from L. bulgaricus CRL450, while B. animalis BB-12 was the least active.

As expected, in general, monosaccharides were the most efficiently metabolized, so when the oligosaccharides from lactulose were the substrates, the fructose consumption was total (with the exception of CRL431 on Ao-OsLu), whereas more than $55 \%$ of glucose was consumed when GOS were the carbon sources. However, galactose was metabolized differently according to the bacteria tested, since the consumption was high for recognized probiotics, especially $B$. animalis BB-12, but significantly less efficient for L. bulgaricus CRL450, leaving a large amount of this monosaccharide. It is well known that in the presence of excess lactose, many L. bulgaricus strains metabolize the glucose moiety of lactose and release galactose into the growth medium. This feature has been associated with the accumulation of galactose in cheeses and with maturation defects. ${ }^{46}$ Regarding disaccharides, lactose was highly metabolized by LAB, leading to a complete consumption for L. bulgaricus CRL450 grown on VivinalGOS, and $79 \%$ for L. casei CRL431 grown on CRL450-GOS, whereas lactulose was consumed between $95 \%$ for $L$. casei CRL431 grown on Ao-OsLu and 51\% for L. bulgaricus CRL450 on CRL450-OsLu. With respect to B. animalis BB-12, low lactose and lactulose consumption was observed, ranging from 32 to $52 \%$. Finally, GOS were more efficiently metabolized, between 32 and 76\%, than OsLu, between 9 and 48\%, regardless of their microbial origin. However, large amount of oligosaccharides from L. bulgaricus CRL450 remained unmetabolized.

As mentioned, it is known that the chemical structure of the oligosaccharides is related to their bioactivities. ${ }^{35}$ Other 


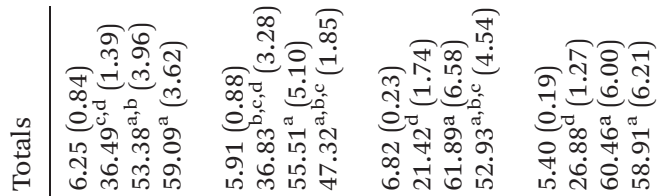

จำ

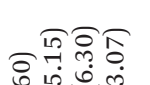

สิก

웅

चु

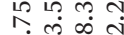

एव.

ले हिंत

लतें

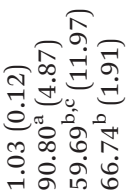

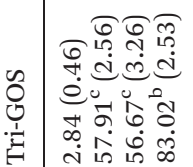

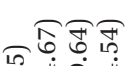

तุ

ㅎํำ

Qت己

勿

فํ.

Tin

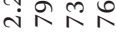

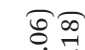

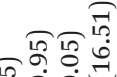

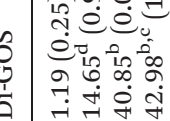

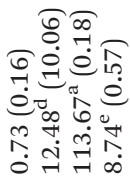

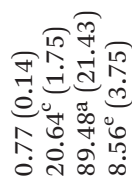

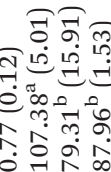

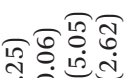

0
0
0

| | | |

$\infty$ จึ

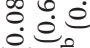

10 는

तथํํำ

F。ำ

e.

तi

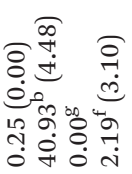

장ำ

ते อें

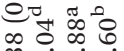

nं

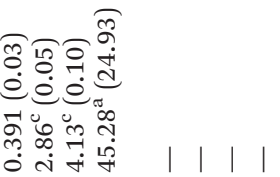

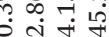
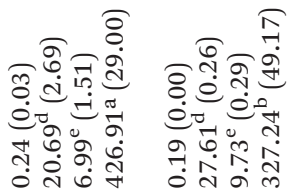

ิㅗํ

․․ㄹ

స్ํำ

पू

อ ํำ studies have evaluated the prebiotic effect of lactose and lactulose derived oligosaccharides on pure cultures of potential probiotic strains by assessing growth and/or metabolite production. ${ }^{31,35,40,47,48}$ However, substrate consumption has not been assessed. Our results show that, although no strong growth was obtained with purified substrates, the microorganisms were able to metabolize to different extents the oligosaccharides derived from lactose and lactulose, in agreement with previous studies using this type of bacteria and oligosaccharides. ${ }^{35,47}$ In addition, the present study revealed the differential consumption of carbohydrates.

\section{Conclusions}

In recent years, the production of tailor-made oligosaccharides synthesized by probiotic- $\beta$-galactosidases has gained attention due to their potential use as specific functional ingredients for improving the composition and activity of gut microbiota. Given the interest of potentially bioactive carbohydrates, novel glycosidases were screened to produce oligosaccharides efficiently. Our results demonstrated that, although a significant number of LAB produced enzymes with transgalactosidase activity, few of them effectively synthesize oligosaccharides. This is the case of L. bulgaricus CRL450, achieving high yields of prebiotic oligosaccharides from lactose (GOS) and lactulose (OsLu), the latter synthetized for the first time with a $\beta$-galactosidase from Lactobacillus sp. These oligosaccharides were mainly composed by $\beta(1 \rightarrow 6)$, and $\beta(1 \rightarrow 3)$ linked trisaccharides. The CRL450-derived oligosaccharide mixtures were consumed and supported growth of the producer and recognized probiotic strains, showing bifidogenic effect. Furthermore, these bacteria were able to metabolize different GOS and OsLu. Since these new oligosaccharides represent a promising alternative for the development of new prebiotic food additives, further studies dealing with the optimization of transgalactosidase conditions as well as the behavior of oligosaccharides formed during in vitro and in vivo fermentation by the complex intestinal microbiota are on course at present.

\section{Conflicts of interest}

There are no conflicts to declare.

\section{Acknowledgements}

This work was supported by PICT 2014-3583 from ANPCyT (Agencia Nacional de Promoción Científica y Tecnológica, Argentina), IC-603 and IC-801 from USPT (Universidad de San Pablo-Tucumán), Project I-COOP_2014_COOPB20099 and EMHE-CSIC 2017 MHE-200047 from CSIC (Consejo Superior de Investigaciones Científicas, España); and AGL2017-84614C2-1-R from MICINN. 


\section{References}

1 F. P. Douillard and W. M. de Vos, Functional genomics of lactic acid bacteria: from food to health, Microb. Cell Fact., 2014, 13, S8.

2 R. J. Vonk, G. A. R. Reckman, H. J. M. Harmsen and M. G. Priebe, Probiotics and lactose intolerance, in Probiotics, ed. E. Rigobelo, InTech, Rijeka, Croatia, 2012, pp. 149-160.

3 J. R. Xavier, K. V. Ramana and R. K. Sharma, $\beta$-Galactosidase: Biotechnological applications in food processing, J. Food Biochem., 2018, 42, e12564.

4 C. Vera, A. Córdova, C. Aburto, C. Guerrero, S. Suárez and A. Illanes, Synthesis and purification of galacto-oligosaccharides: state of the art, World J. Microbiol. Biotechnol., 2016, 32(197), 1-20.

5 G. Zárate, G. Sáez, and A. Pérez Chaia, Microbial transformation of lactose: potential of $\beta$-galactosidases for probiotic and prebiotic purposes, in Lactose: structure, food industry applications and role in disorders, ed. D. Green and E. Lee, Nova Science Publishing, USA, 2013, pp. 1-50.

6 X. Y. Chen and M. G. Gänzle, Lactose and lactose-derived oligosaccharides: More than prebiotics?, Int. Dairy J., 2017, 67, 61-72.

7 E. E. Tymczyszyn, M. I. Santos, M. D. C. Costa, A. Illanes and A. Gomez-Zavaglia, History, synthesis, properties, applications and regulatory issues of prebiotic oligosaccharides, in Carbohydrates Applications in Medicine, ed. M. H. Gil, Research Signpost, Kerala, India, 2014, pp. 127-154.

8 G. R. Gibson, R. Hutkins, M. E. Sanders, S. L. Prescott, R. A. Reimer, S. J. Salminen, K. Scott, C. Stanton, K. S. Swanson, P. D. Cani, K. Verbeke and G. Reid, The International Scientific Association for Probiotics and Prebiotics (ISAPP) consensus statement on the definition and scope of prebiotics, Nat. Rev. Gastroenterol. Hepatol., 2017, 14, 491-502.

9 G. T. Macfarlane, H. Steed and S. Macfarlane, Bacterial metabolism and health-related effects of galacto-oligosaccharides and other prebiotics, J. Appl. Microbiol., 2008, 104, 305-344.

10 S. López-Sanz, A. Montilla, F. J. Moreno and M. Villamiel, Stability of oligosaccharides derived from lactulose during the processing of milk and apple juice, Food Chem., 2015, 183, 64-71.

11 Y. Wang, Prebiotics: Present and future in food science and technology, Food Res. Int., 2009, 42, 8-12.

12 A. Cardelle-Cobas, M. Villamiel, A. Olano and N. Corzo, Study of galactooligosaccharides formation from lactose using Pectinex-Ultra SP-L, J. Sci. Food Agric., 2008, 88, 954961.

13 A. Cardelle-Cobas, A. Olano, G. Irazoqui, C. Giacomini, F. Batista-Viera, N. Corzo and M. Corzo-Martínez, Synthesis of oligosaccharides derived from lactulose (OsLu) using soluble and immobilized Aspergillus oryzae $\beta$-galactosidase, Front. Bioeng. Biotechnol., 2016, 4, 21.
14 C. Guerrero, C. Vera, F. Acevedo and A. Illanes, Simultaneous synthesis of mixtures of lactulose and galacto-oligosaccharides and their selective fermentation, J. Biotechnol., 2015, 209, 31-40.

15 C. Martínez-Villaluenga, A. Cardelle-Cobas, N. Corzo, A. Olano and M. Villamiel, Optimization of conditions for galactooligosaccharide synthesis during lactose hydrolysis by $\beta$-galactosidase from Kluyveromyces lactis (Lactozym 3000 L HP G), Food Chem., 2008, 107, 258264.

16 C. Martínez-Villaluenga, A. Cardelle-Cobas, A. Olano, N. Corzo, M. Villamiel and M. L. Jimeno, Enzymatic synthesis and identification of two trisaccharides produced from lactulose by transgalactosylation, J. Agric. Food Chem., 2008, 56, 557-563.

17 O. Hernández-Hernández, F. Montañés, A. Clemente, F. J. Moreno and M. L. Sanz, Characterization of galactooligosaccharides derived from lactulose, J. Chromatogr. A, 2011, 1218, 7691-7696.

18 P. Urrutia, B. Rodriguez-Colinas, L. Fernandez-Arrojo, A. O. Ballesteros, L. Wilson, A. Illanes and F. J. Plou, Detailed analysis of galactooligosaccharides synthesis with $\beta$-galactosidase from Aspergillus oryzae, J. Agric. Food Chem., 2013, 61, 1081-1087.

19 M. Corzo-Martínez, P. Copoví, A. Olano, F. J. Moreno and A. Montilla, Synthesis of prebiotic carbohydrates derived from cheese whey permeate by a combined process of isomerisation and transgalactosylation, J. Sci. Food Agric., 2013, 93, 1591-1597.

20 H. Yin, J. B. Bultema, L. Dijkhuizen and S. S. van Leeuwen, Reaction kinetics and galactooligosaccharide product profiles of the $\beta$-galactosidases from Bacillus circulans, Kluyveromyces lactis and Aspergillus oryzae, Food Chem., 2017, 225, 230-238.

21 C. Sabater, A. Fara, J. Palacios, N. Corzo, T. Requena, A. Montilla and G. Zárate, Synthesis of prebiotic galactooligosaccharides from lactose and lactulose by dairy propionibacterias, Food Microbiol., 2019, 77, 93-105.

22 T. Goulas, A. Goulas, G. Tzortzis and G. R. Gibson, Expression of four $\beta$-galactosidases from Bifidobacterium bifidum NCIMB41171 and their contribution on the hydrolysis and synthesis of galactooligosaccharides, Appl. Microbiol. Biotechnol., 2009, 84, 899-907.

23 C. A. Hsu, S. L. Lee and C. C. Chou, Enzymatic production of galactooligosaccharides by $\beta$-galactosidase from Bifidobacterium longum BCRC 15708, J. Agric. Food Chem., 2007, 55, 2225-2230.

24 A. Osman, G. Tzortzis, R. A. Rastall and D. A. Charalampopoulos, Comprehensive investigation of the synthesis of prebiotic galactooligosaccharides by whole cells of Bifidobacterium bifidum, NCIMB 41171, J. Biotechnol., 2010, 150, 140-148.

25 B. Splechtna, T. H. Nguyen and D. Haltrich, Production of Prebiotic Galacto- Oligosaccharides from Lactose using $\beta$-Galactosidases from Lactobacillus reuteri, J. Agric. Food Chem., 2006, 54, 4999-5006. 
26 T. H. Nguyen, B. Splechtna, S. Krasteva, W. Kneifel, K. D. Kulbe, C. Divne and D. Haltrich, Characterization and molecular cloning of a heterodimeric $\beta$-galactosidase from the probiotic strain Lactobacillus acidophilus, R22, FEMS Microbiol. Lett., 2007, 269, 136-144.

27 M. Carević, M. Vukašinović-Sekulić, M. Corović, H. Rogniaux, D. Ropartz, D. Velicković and D. Bezbradica, Evaluation of $\beta$-galactosidase from Lactobacillus acidophilus as biocatalyst for galacto-oligosaccharides synthesis: Product structural characterization and enzyme immobilization, J. Biosci. Bioeng., 2018, 126, 697-704.

28 D. Gobinath and S. G. Prapulla, Permeabilized probiotic Lactobacillus plantarum as a source of $\beta$-galactosidase for the synthesis of prebiotic galactooligosaccharides, Biotechnol. Lett., 2014, 36, 153-157.

29 S. Iqbal, T. H. Nguyen, T. T. Nguyen, T. Maischberger and D. Haltrich, $\beta$-Galactosidase from Lactobacillus plantarum WCFS1: Biochemical characterization and formation of prebiotic galacto-oligosaccharides, Carbohydr. Res., 2010, 345, 1408-1416.

30 L. Lu, S. Xu, R. Zhao, D. Zhang, Z. Li, Y. Li and M. Xiao, Synthesis of galactooligosaccharides by CBD fusion $\beta$-galactosidase immobilized on cellulose, Bioresour. Technol., 2012, 116, 327-333.

31 B. A. Rabiu, A. J. Jay, G. R. Gibson and R. A. Rastall, Synthesis and fermentation properties of novel galactooligosaccharides by $\beta$-galactosidases from Bifidobacterium species, Appl. Environ. Microbiol., 2001, 67, 2526-2530.

32 O. Hernández, A. I. Ruiz-Matute, A. Olano, F. J. Moreno and M. L. Sanz, Comparison of fractionation techniques to obtain prebiotic galactooligosaccharides, Int. Dairy J., 2009, 19, 531-536.

33 J. Huebner, R. L. Wehling and R. W. Hutkins, Functional activity of commercial prebiotics, Int. Dairy J., 2007, 17, 770-775.

34 A. Cardelle-Cobas, N. Corzo, A. Olano, C. Peláez, T. Requena and M. Ávila, Galactooligosaccharides derived from lactose and lactulose: influence of structure on Lactobacillus, Streptococcus, and Bifidobacterium growth, Int. J. Food Microbiol., 2011, 149, 81-87.

35 A. Cardelle-Cobas, A. Olano, N. Corzo, M. Villamiel, M. Collins, S. Kolida and R. A. Rastall, In vitro fermentation of lactulose-derived oligosaccharides by mixed fecal microbiota, J. Agric. Food Chem., 2012, 60, 2024-2032.

36 A. Cardelle-Cobas, C. Martínez-Villaluenga, M. L. Sanz and A. Montilla, Gas chromatographic-mass spectrometric analysis of galactosyl derivatives obtained by the action of two different $\beta$-galactosidases, Food Chem., 2009, 114, 10991105.

37 S. Chockchaisawasdee, V. I. Athanasopoulos, K. Niranjan and R. A. Rastall, Synthesis of galacto-oligosaccharide from lactose using $\beta$-galactosidase from Kluyveromyces lactis: Studies on batch and continuous UF membrane-fitted bioreactors, Biotechnol. Bioeng., 2005, 89, 434-443.
38 F. Depeint, G. Tzortzis, J. Vulevic, K. I'Anson and G. R. Gibson, Prebiotic evaluation of a novel galactooligosaccharide mixture produced by the enzymatic activity of Bifidobacterium bifidum NCIMB 41171, in healthy humans: a randomized, double-blind, crossover, placebo-controlled intervention study, Am. J. Clin. Nutr., 2008, 87, 785-791.

39 S. Kittibunchakul, T. Maischberger, K. Domig, W. Kneifel, H. M. Nguyen, D. Haltrich and T. H. Nguyen, Fermentability of a novel galacto-oligosaccharide mixture by Lactobacillus spp. and Bifidobacterium spp., Molecules, 2018, 23, 3352.

40 A. Ferreira-Lazarte, P. Gallego-Lobillo, F. J. Moreno, M. Villamiel and O. Hernández-Hernández, In vitro digestibility of galactooligosaccharides: effect of the structural features on their intestinal degradation, J. Agric. Food Chem., 2019, 67(16), 4662-4670.

41 M. C. Marín-Manzano, L. Abecia, O. HernándezHernández, M. L. Sanz, A. Montilla, A. Olano, L. A. Rubio, F. J. Moreno and A. Clemente, Galacto-oligosaccharides derived from lactulose exert a selective stimulation on the growth of Bifidobacterium animalis in the large intestine of growing rats, J. Agric. Food Chem., 2013, 61, 7560-7567.

42 A. Gosling, G. W. Stevens, A. R. Barber, S. E. Kentish and S. L. Gras, Recent advances refining galactooligosaccharide production from lactose, Food Chem., 2010, 121, 307-318.

43 A. Amaretti, T. Bernardi, E. Tamburini, S. Zanoni, M. Lomma, D. Matteuzzi and M. Rossi, Kinetics and metabolism of Bifidobacterium adolescentis, $\mathrm{MB}$ 239 growing on glucose, galactose, lactose, and galactooligosaccharides, Appl. Environ. Microbiol., 2007, 73(11), 36373644.

44 M. Barboza, D. A. Sela, C. Pirim, R. G. LoCascio, S. L. Freeman, J. B. German, D. A. Mills and C. B. Lebrilla, Glycoprofiling bifidobacterial consumption of galactooligosaccharides by mass spectrometry reveals strainspecific, preferential consumption of glycans, Appl. Environ. Microbiol., 2009, 75, 7319-7325.

45 P. K. Gopal, P. A. Sullivan and J. B. Smart, Utilisation of galacto-oligosaccharides as selective substrates for growth by lactic acid bacteria including Bifidobacterium lactis DR10 and Lactobacillus rhamnosus DR20, Int. Dairy J., 2001, 11, 19-25.

46 M. W. Hickey, A. J. Hillier and G. R. Jago, Transport and metabolism of lactose, glucose, and galactose in homofermentative lactobacilli, Appl. Environ. Microbiol., 1986, 51, 825-831.

47 O. Hernández-Hernández, A. Muthaiyan, F. J. Moreno, A. Montilla, M. L. Sanz and S. C. Ricke, Effect of prebiotic carbohydrates on the growth and tolerance of Lactobacillus, Food Microbiol., 2012, 30, 355-361.

48 S. Y. Oh, S. Y. Youn, M. S. Park, H. G. Kim, N. I. Baek, Z. Li and G. E. Ji, Synthesis of $\beta$-galactooligosaccharide using bifidobacterial $\beta$-galactosidase purified from recombinant Escherichia coli, J. Microbiol. Biotechnol., 2017, 27, 1392-1400. 